\title{
Selfie-Portraits: Agnès Varda, JR, and the Politics of Sharing
}

\author{
Tomas Elliott
}

DOI: 10.15664/fcj.v18i1.2256

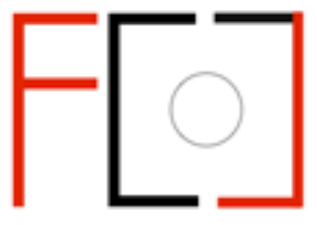

Frames Cinema Journal ISSN 2053-8812

Issue 18 (Jun 2021)

http://www.framescinemajournal.com

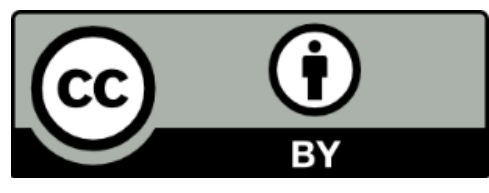




\section{Selfie-Portraits: Agnès Varda, JR, and the Politics of Sharing}

Tomas Elliott

About once a week I wake up to a message on my phone that tells me: "You have a new memory." The second person address is always disarming: "Do I?" I respond. But my phone is generally right. Clicking on the link brings up a series of photos that I supposedly took at one time or another and that have now found their way into the obscure recesses of my phone. I had forgotten them as soon as they were taken, and they now seem entirely new.

It is this ephemerality of the personal snapshot, particularly in its most contemporary form, the phone camera selfie, that filmmaker Agnès Varda and photographer JR try to disrupt in their 2017 ensemble piece, Visages Villages. In an early scene in the film, Varda tells us that she takes photos of people so that they will not "fall down the holes in [her] memory." While photography had always played a significant role in Varda's aesthetics, in Visages Villages, it is used to transform personal portraits into public monuments. In this way, Varda and JR strive to create a new kind of community, based on a politics of sharing. This involves bringing a new kind of awareness to how we take, consume, and distribute phone camera images of one another, an awareness that Varda and JR both model and facilitate in their film.

The idea that the photographic portrait sits in a liminal space between remembering and forgetting is nothing new. In Camera Lucida, Roland Barthes famously quoted Kafka's comment that "we photograph things in order to drive them out of our minds." ${ }^{1}$ Barthes, for his part, reflects on the gap that separates the viewer from the photographs he or she observes: "with regard to many of these photographs, it was History which separated me from them."2 But the logic of the phone camera seems to make that disconnect even more palpable. Given that I now carry around all of 
my photos with me, literally at my fingertips, I am all the more aware of how divorced I feel from them. When my phone shows me a selfie and tells me that I have a "new memory," it is not just that I end up looking, like Barthes did, "at eyes that looked at the Emperor"; the more unnerving reality is that I am looking at my eyes as they once looked at me. ${ }^{3}$ Those are eyes that I no longer know.

Given the personalism of this discussion (Geoffrey Batchen writes that Camera Lucida inaugurated a "narcissistic way of speaking" about photography), I find Visages Villages notable for how it disrupts the form of the self-reflective essay or personal film. ${ }^{4}$ Firstly, and most obviously, the film is a dialogue rather than a monologue, a generally friendly but occasionally testy conversation between two artists. Secondly, its ethos seems to be based primarily on coming to know the lives of others rather than oneself ("we're getting to know each other", Varda comments at one point). Both the film's politics and its aesthetics, in other words, are based on sharing rather than self-discovery, recalling what So Mayer has identified as the importance of exchange in cinema, most notably in the works of another feminist filmmaker, Sally Potter. Mayer argues that Potter's work is based on a "politics of love" created through an exchange "between characters, and between the film and the viewer". ${ }^{5}$ We might see Varda's and JR's project as a similar attempt "to restore love to its political efficacy" through sharing. ${ }^{6}$

This is evident from the very start of the film, as the two artists reflect on each other's work, rather than their own: "I remember the images from your films," JR tells Varda (in French, the emphasis is specifically on not forgetting: "je n'ai pas oublié les images de tes films"). He gives a few examples: “Cléo's face ... Mur Murs in Los Angeles ... Those giant murals made such an impression on me." Varda, in turn, tells JR what she loves about his work: "I loved seeing out the train window the eyes you pasted on cisterns." If this seems self-congratulatory, this sense 
quickly passes, as the film's main focus is not on elevating JR and Varda, but on extending this ethos of sharing to the people whom they encounter. It is this focus, moreover, that gives the film its structure. In an early scene in which they discuss the kind of film that they want to make, Varda tells JR: "What I liked was meeting amazing people by chance." "Chance," she continues, "has always been my best assistant." From this point on, the film takes the form of a journey that goes "here and there," as JR and Varda travel across France, seeking out people and their unique, personal stories.

Along the way, Varda and JR encounter people rooted in their everyday lives, many of whom are either personally or socially isolated: a farmer who takes care of 500 acres on his own, for example, or a group of women whose husbands work as sea freight operators. In an early scene, the duo visit an old mining village and speak with a woman named Jeanine. She is "the sole survivor" in a block of old miners' homes that are soon to be demolished. Her life and her memory are deeply connected to the space in which she lives: "I have too many memories here," she tells us. "No one can understand what we lived through." In response, Varda's and JR's task is to allow other people to visualise those memories, to recognise that, even if they cannot "understand" what Jeanine's life was like, they can still "pay homage" to her, as Varda puts it. Using the photo booth contained within JR's van, JR and Varda print out a large-scale, black-and-white portrait of Jeanine, which they then attach to the house in which she lives, transforming her home into a piece of art, a public work that anyone can observe. 


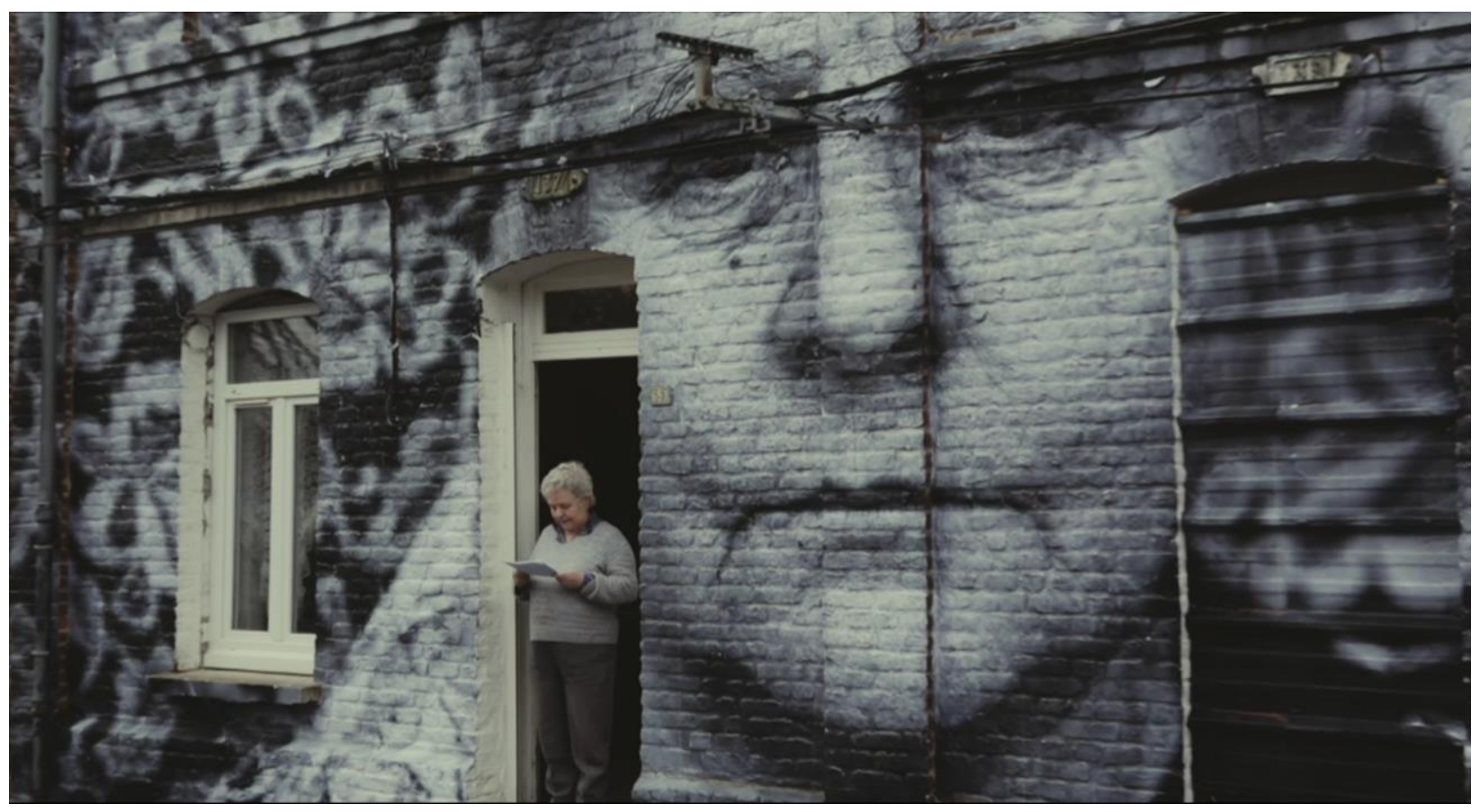

Figure 1: Jeanine stands in the doorway of her house, surrounded by her large-scale portrait. Visages Villages, 2017, dir. Agnès Varda.

The most important part of this process, though, is what happens next. Once Jeanine's house becomes an artwork, people are encouraged to gather around it. Like crowds in art galleries or tourists visiting monuments around the world, these people begin taking selfies and pictures outside Jeanine's house, linking her life with theirs. While it is easy to be cynical about the circle of narcissism that this process entails (or, more mundanely, to recall the annoyance one may sometimes feel when phone cameras crowd around paintings in a gallery), it is Varda's and JR's ability to let people share in the lives of others that marks the true power of their political project. In Varda's and JR's hands, and then in the hands of people on their phones, Jeanine's story rises out of obscurity to the status of public art, creating what Richard Brody has called the film's 'transideological vision of curiosity, empathy, and dignity." ${ }^{\prime 7}$ In this scene, therefore, the phone camera becomes an important focal point for a new community, even though it is neither the technology that JR uses to create his portraits nor the medium through which we, as film viewers, experience them. The groups of young people who photograph Jeanine's home and take selfies next to the 
miners' images provide an example of phone cameras being used to foster connections with others, celebrating the social, artistic, and political power of mobile phone images.

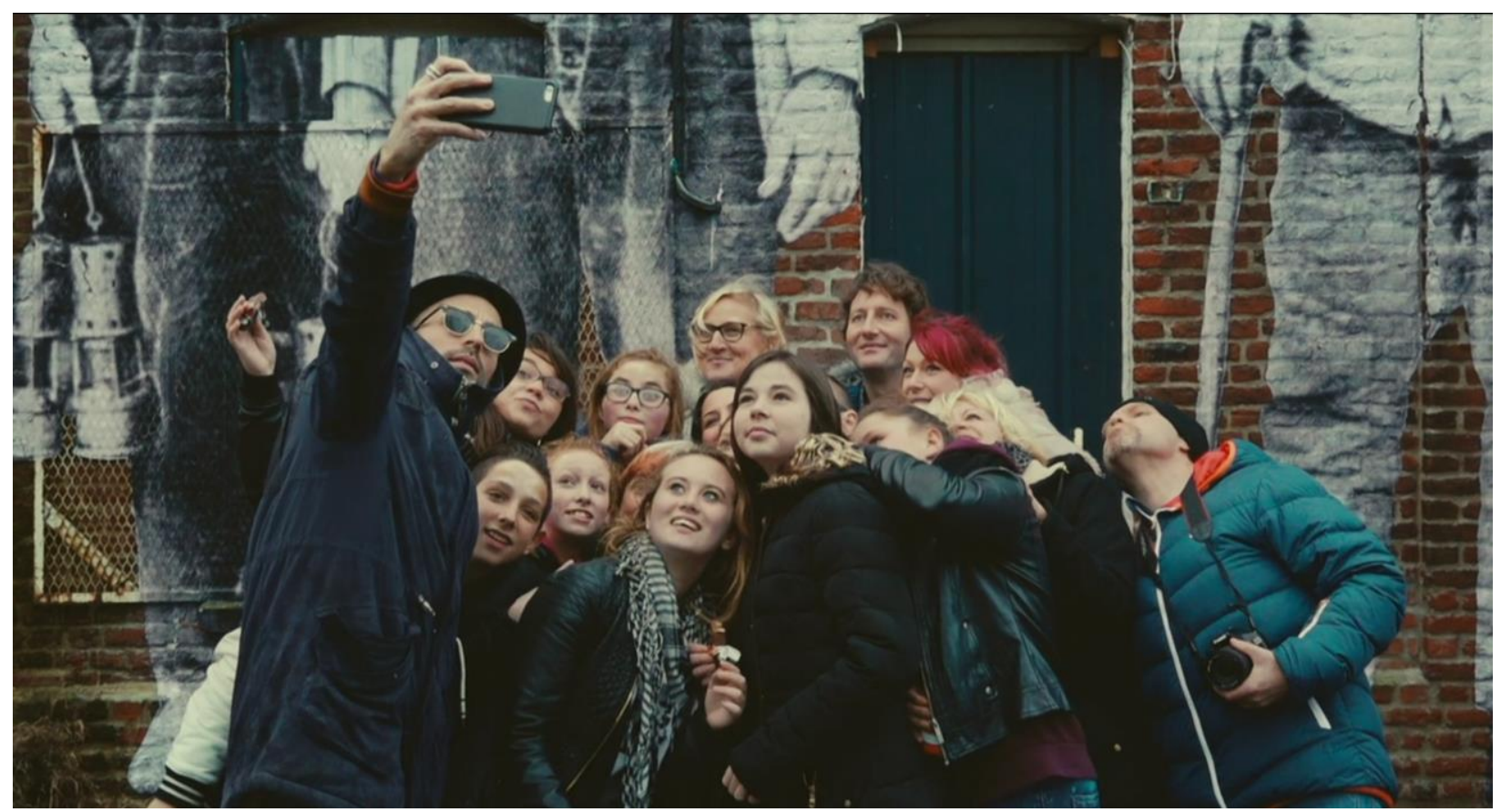

Figure 2: A group of people take a selfie in front of JR's murals of miners. Visages Villages, 2017, dir. Agnès Varda.

This kind of communal activity was something that Varda cultivated, in different ways, throughout her career. In her final film, Varda par Agnès (2019), Varda picked out three words that she said had motivated her: "inspiration, creation, sharing." The concept of "sharing" has a prominent place in many of her late works, from films like Les glaneurs et la glaneuse (2000) to Les plages d'Agnès (2008), where she frequently picks up on the small titbits of other people's lives so that she can share them with the world. As she puts it in Varda par Agnès: "We don't make films to watch them alone; we make films to show them."

It is primarily in Visages Villages, though, that we see how that project takes on new meaning with the modern technological apparatus that most effectively combines image production with communication: the mobile phone. It was while she was making this film that Varda started her own Instagram account, opening with a typically quirky image that she captioned 
"welcome cat", self-reflexively recalling the feline friends found throughout her films. As Varda quickly adapted to the half-private, half-public realm of Instagram, the platform became a regular mechanism for her documentary aesthetic, as well as a publicity hub for Visages Villages. Varda's and JR's accounts played off against one another, and JR's one million Instagram followers were frequently referenced in the build-up to the film's release. There was undoubtedly a commercial impetus behind this. Visages Villages was entirely crowdfunded, so Varda and JR presumably relied on the platform to connect with supporters and donors. At the same time, however, this crowd-sourced approach also allowed Varda and JR to adopt their free-wheeling approach to filmmaking, travelling across France almost at random. In this way, the process of producing and funding the film helped to orientate and structure its content, bringing together isolated individuals through new forms of multimedia connectivity.

agnes.varda
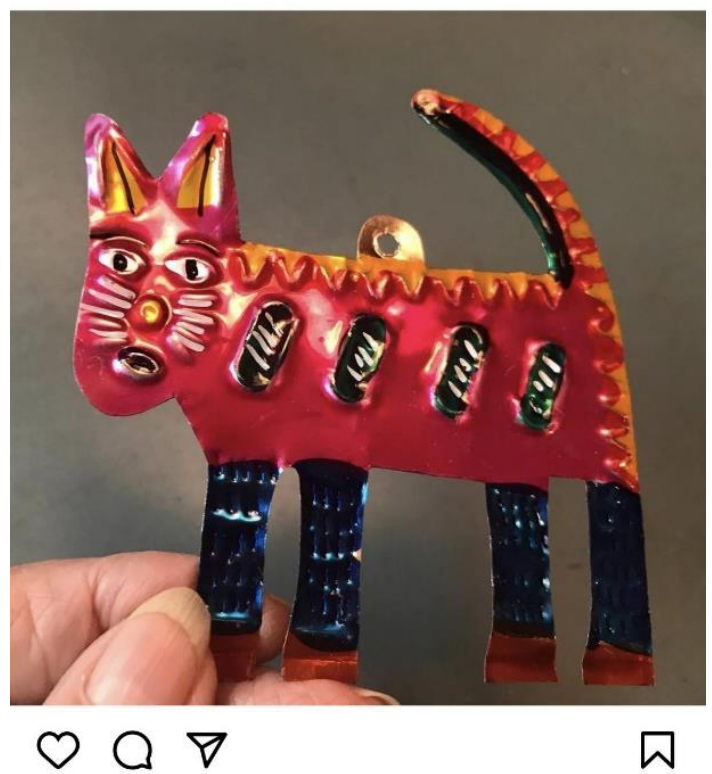

(3) Liked by jr and 3,884 others

agnes.varda The welcome cat \#cinema \#art \#poesie \#photography \#liberteegalitefraternite

View all 100 comments
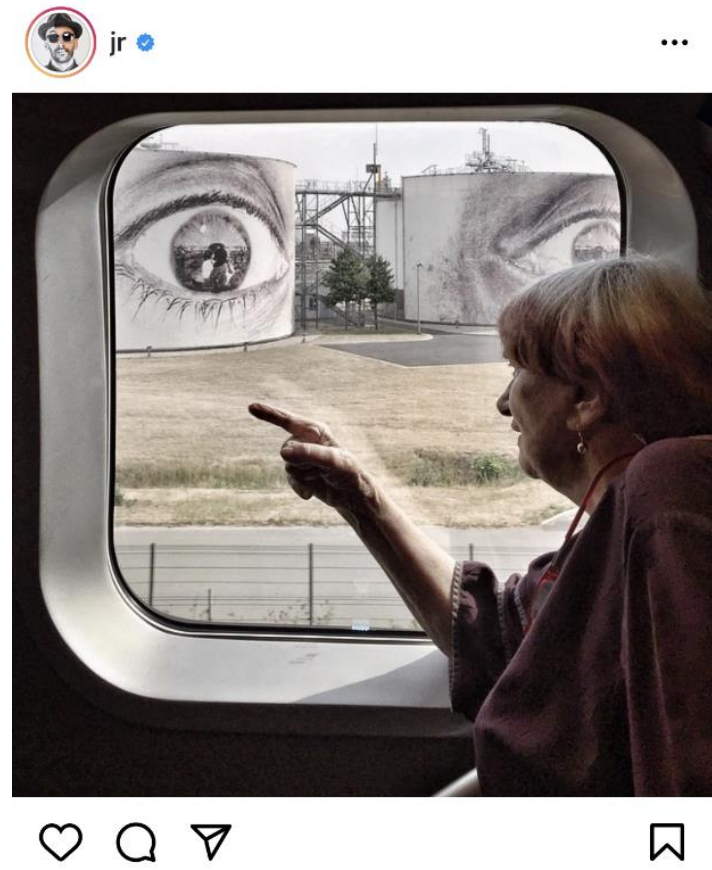

10,384 likes

jr Each time Agnes goes by this eyes she send me her warmest regards \#JRxAgnesVarda

View all 46 comments

Figure 3 and 4: Instagram posts from Agnès Varda (left, featuring "The welcome cat", 6 May 2017) and JR (right, featuring Varda looking at JR's murals on cisterns, 4 July 2015). 
In the film, this kind of community building works not only in the present but also in the past, as the new technology of the phone camera meets with earlier forms of image production. In another of their many encounters, Varda and JR speak to a brother and sister in Bonnieux, a small town in southeast France. The siblings show Varda and JR a daguerreotype of their greatgrandmother and great-grandfather. From a digital scan that interlayers this nineteenth-century image into an oval picture frame, JR creates a supersized version of this old family portrait, which is again then printed and glued to the wall of their family home. The family speaks to Varda and JR as they sit in front of their personalised portrait gallery, and their excitement is palpable. The brother tells Varda: "It's a picture of our ancestors on their wall. On their very own façade. It's truly a great joy." Sparked by this excitement, the moment launches a new kind of participation and sharing. Speaking off-camera, Varda says that she can tell that the brother and sister "want to be part" of this process and to involve themselves in the new artistic environment that she and JR have created. The siblings take out their phones, and the brother announces that it is "selfie time." Varda encourages them, announcing that the whole process is about "transmission": the transmission of a personal legacy into the public domain; the transmission of a genealogical line from great-grandparents to great-grandchildren; the transmission of a memory across multiple generations.

This process also continues beyond the people featured on screen. The sister tells us that her daughter has used a shot of the mural "for her Facebook profile," and it is precisely this kind of amateur image creation and distribution that Varda hopes to inspire. While taking a picture of another mural with his phone later on, a young boy tells Varda, "I'm not a specialist," and this is exactly the point. Varda and JR use their own technical skills to create artworks that allow others to share them. By raising the private lives of strangers to the status of public monuments, Visages 
Villages invites entire communities of non-specialists to participate in a new kind of memorialisation, building history from the ground up. Rather than monuments being imposed on public spaces by governments or councils (leading to the debates over statues that have gripped so many Anglo-European cities in recent years), JR and Varda build monuments out of the lives and memories of the people who occupy those spaces today.

That said, the film also captures some of the ambivalence of taking and sharing phone camera photos. In an encounter that immediately follows the one with the brother and sister, JR and Varda photograph a young woman whom Varda has met in a café. Once they affix her image to a wall on the other side of the street, however, it becomes clear that the woman was not fully informed about (or had not fully considered) the reality of what the process would entail. "I didn't realize that the picture would be so big. I worked nearby. Seeing people take my picture every day bothered me... I'm pretty shy, so it made me uncomfortable."

"I wish it had made you feel good," Varda replies, but the individuals taking photos and selfies on their phones are clearly distressing to the subject. "It's pretty weird to see a picture of yourself on the internet, on Instagram, everywhere," she says. The woman, who is named and thanked in the credits, must have given her consent to appear in the film. In that sense, she was aware that her image would enter into a logic of distribution and a certain forum for reproduction and dissemination. But the phone cameras, specifically, distress her because they transform her into a tourist attraction. "She's been photographed millions of times," the owner of the café remarks. "We hired her as a waitress back in late May, early summer. Now she's become Bonnieux’s most famous face."

The moment is a counterpoint to the sense of community that the film's politics of sharing hopes to create. The woman highlights the negative side to social media's valuation of distribution 
networks and the "like" economy. We do not hear from the waitress after her boss describes the "millions of photos" taken of her, but it is clear that her image has taken on a life of its own, and the waitress's complaints bring to mind the difficulties that women in particular face around issues of non-consensual image sharing, as well as contemporary debates about the "right to erasure" and the "right to be forgotten". ${ }^{8}$

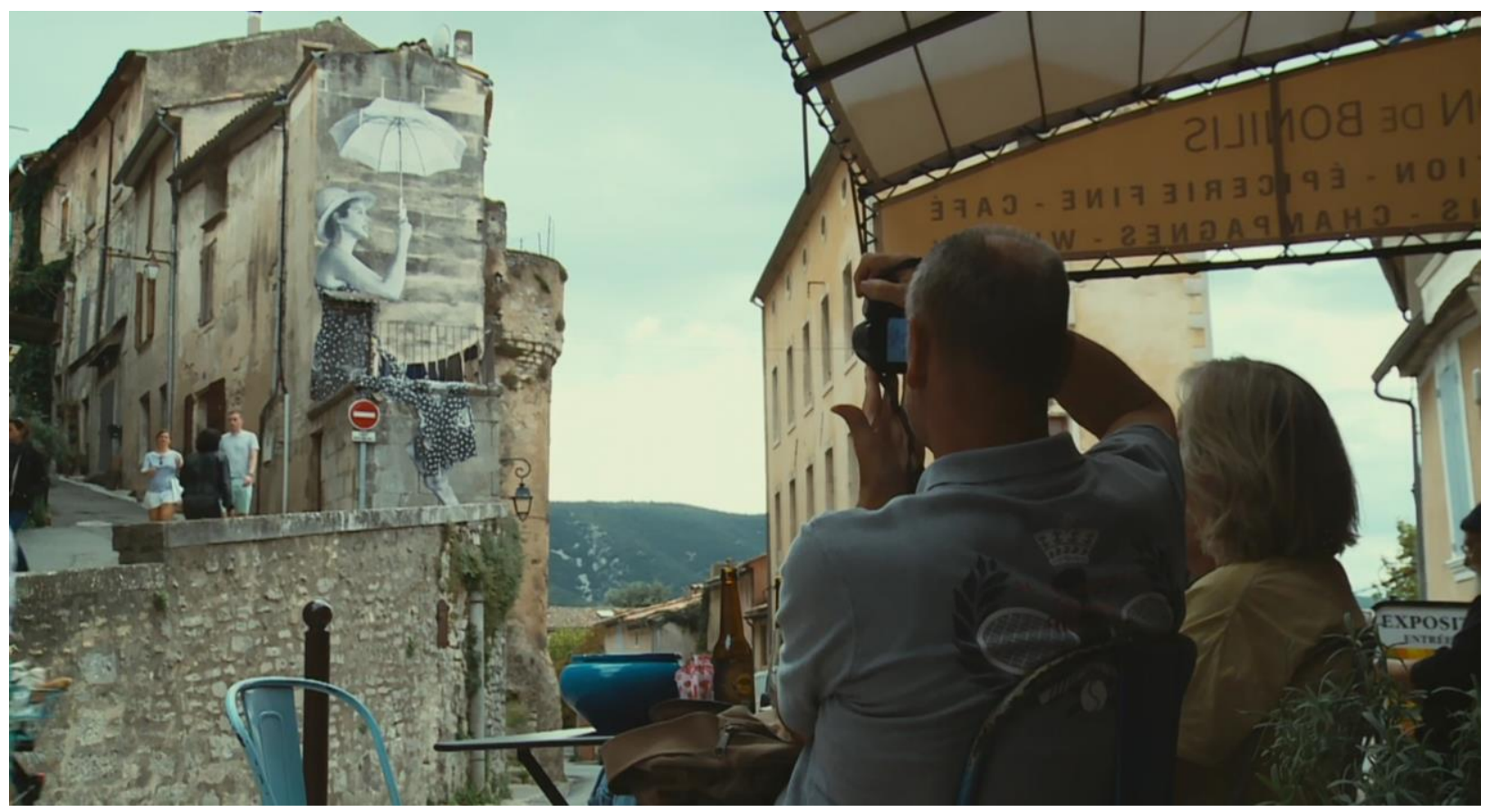

Figure 5: Tourists take photos of a mural of a woman in Bonnieux. Visages Villages, 2017, dir. Agnès Varda.

In fact, watching the film now, after Varda's death, it is hard not to reflect on how she herself might have responded to such calls for a "right to be forgotten." In the film, Varda frequently meditates on her own mortality. At one point, when she and JR visit the grave of the photographer Henri Cartier-Bresson, she claims that she is "looking forward" to death. When JR asks why, she simply responds: "Because it will be finished." There is a sense, therefore, that even though Varda and JR place memory and memorialisation at the heart of their political and aesthetic projects, Varda also recognises that being able to forget and be forgotten may also be a powerful release, a release whose end point is, ultimately, death. 
This longing for release seems to build as the film progresses, and the viewer gains a profound sense of the weight of history Varda herself carries with her. This takes centre stage in the film's closing scene, when two of its most pronounced absences coincide - one of them highlighting the need to be remembered, the other the importance of the right to be forgotten. The first absence is that of Varda's deceased husband, Jacques Demy, who died in 1990. The second absence is that of Jean-Luc Godard, who stands Varda and JR up for an appointment at his house in Switzerland. When he does not show up, Godard leaves Varda a "cryptic message" from their past: "À la ville de Douarnenez. Du côté de la côte." The first line, which means "In the town of Douarnenez," is a reference to a restaurant where Varda, Godard, and Jacques Démy used to eat together. It was also what Godard wrote to Varda when her husband died. The second line is the title an early documentary by Varda from 1958, called Along the Coast in English. Varda, who is visibly moved to tears, tells the camera, "if he wanted to hurt me, he succeeded," and she labels Godard "a dirty rat."

The hurt, of course, comes from the variously distributed forms of memory and forgetfulness that the scene conjures up. Godard, who is remembered in Varda's film for covering up his face, like JR, behind dark glasses (and who only appears in the film in a clip from Cléo de 5 à 7 that Varda shows JR on her iPad), refuses to come alive again in Visages Villages as another of Varda's images. In this way, he interrupts her aesthetics of sharing, perhaps insisting on his own "right to erasure” ("he's very solitary, a solitary philosopher," Varda tells JR). He insists on his right to erasure, though, only by wielding images and memories whose pain, in these late years, Varda can neither afford nor hope to forget. "It means that he knows I'm here," she says. "It means he's thinking of Jacques; but it's not very funny." It seems, in other words, that in these genuinely poignant scenes, Varda is haunted as much by the images of people she cannot forget as by those 
for whom she is prevented from memorialising. As with the young woman in Bonnieux, here we encounter a fraught space in which different people contest the politics, aesthetics, and ethics involved in the sharing of their personal image. Godard's non-appearance highlights the nuanced situatedness of image sharing, suggesting that the types of community that Varda and JR hope to construct depend first and foremost on participants consenting to the distribution of their image.

Despite these important issues, when I scroll through Varda's Instagram account today, I am ultimately struck by the enduring power of her politics of sharing. Unintentionally, her final post ended up recalling her first. It is an image of her cat lounging in a director's chair, which Varda herself will never again occupy. The image is dated 18 March 2019, not even two weeks before her death. The post continues to garner new comments every few weeks. I wonder how long this image, which was presumably not intended to be her last, will stand as a permanent testament to her life. This unanticipatedly permanent image, captured and posted in the instant but now recalling a static JR mural, suggests to me that living up to the full force of Varda's politics of sharing requires us to bring a newfound awareness to how we create and distribute images, on our phones and elsewhere. It demands that we do not simply let our phone camera images drift into the holes of our memory. At the same time, Varda's legacy invites us to use our images to uplift those who want to be uplifted, rather than focussing on ourselves. Grappling with this in a new age of distributed social media will always be difficult, but it might stand as a fitting continuation of Varda's and JR's complex, dynamic, and generous art. 


\section{agnes.varda}

Paris, France

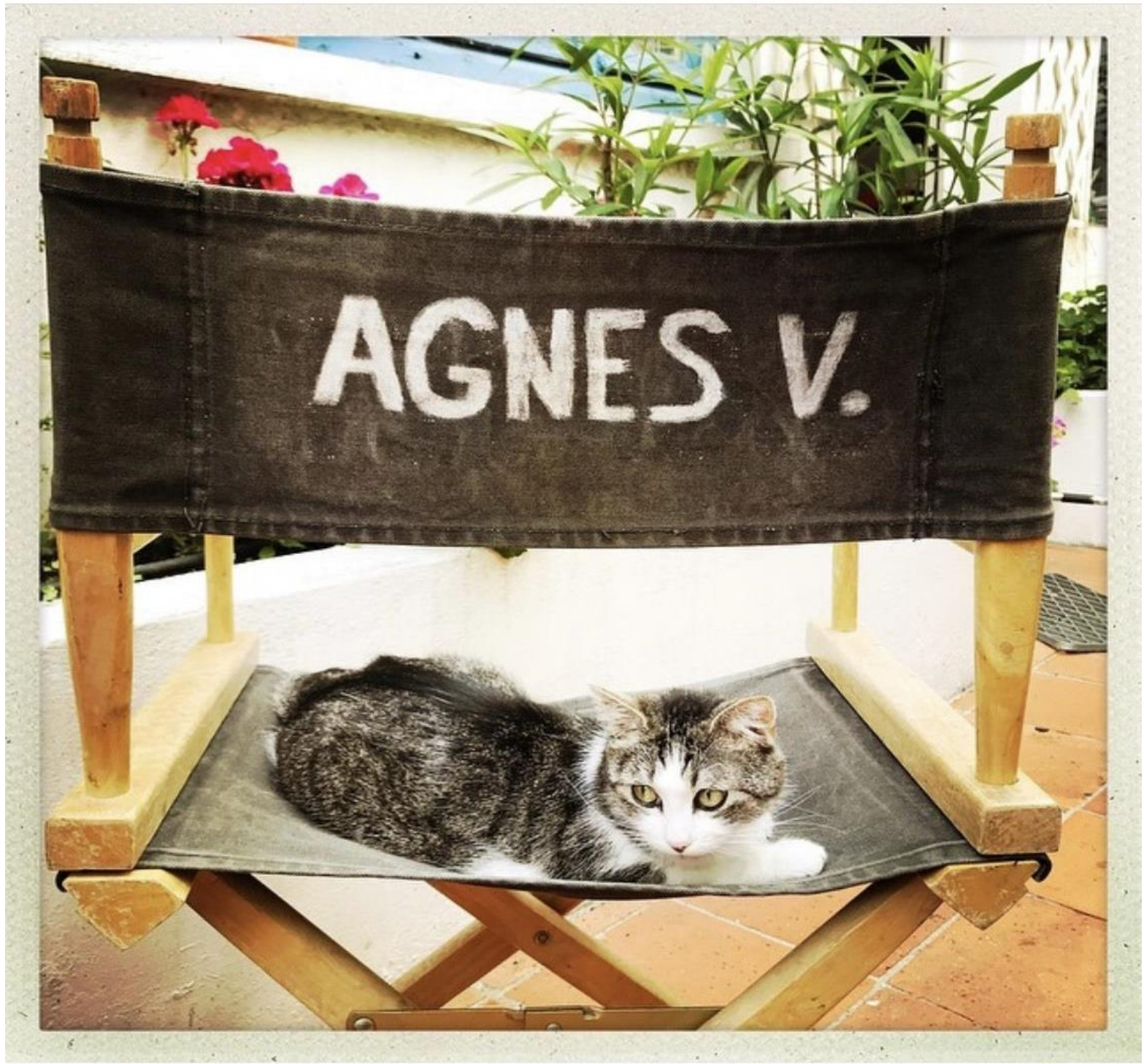

$\bigcirc \bigcirc \nabla$

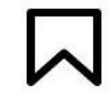

: Liked by jr and 36,116 others

agnes.varda Nini vous signale la diffusion ce soir lundi 18 mars sur \#arte à $22 \mathrm{~h} 40$ de mon \#documentaire sur mes causeries... more

Figure 6: Agnès Varda's final Instagram post, 18 March 2019. 


\section{Notes}

${ }^{1}$ Roland Barthes, Camera Lucida: Reflections on Photography, trans. Richard Howard (London: Vintage, 2020), 67.

${ }^{2}$ Barthes, Camera, 76.

${ }^{3}$ Barthes, Camera, 3.

${ }^{4}$ Geoffrey Batchen, "Palinode: An Introduction to Photography Degree Zero," in Photography Degree Zero, ed. Geoffrey Batchen (Cambridge: MIT Press, 2011), 3.

${ }^{5}$ So Mayer, The Cinema of Sally Potter: A Politics of Love (New York and London: Wallflower Press, 2009), 23.

${ }^{6}$ Mayer, Cinema, 26.

7 Richard Brody, “Agnès Varda and JR's Faces Places honors ordinary people on a heroic scale," New Yorker, October 10, 2017, www.newyorker.com/culture/richard-brody/agnes-vardaand-jrs-faces-places-honors-ordinary-people-on-a-heroic-scale.

8 "Right to erasure ('right to be forgotten')," Article 17, GDPR, gdpr-info.eu/art-17-gdpr/.

\section{Bibliography}

Barthes, Roland. Camera Lucida: Reflections on Photography. Translated by Richard Howard. London: Vintage, 2020.

Batchen, Geoffrey. "Palinode: An Introduction to Photography Degree Zero." In Photography Degree Zero, edited by Geoffrey Batchen, 3-30. Cambridge: MIT Press, 2011.

Brody, Richard. “Agnès Varda and JR's Faces Places honours ordinary people on a heroic scale," New Yorker, October 10, 2017, www.newyorker.com/culture/richard-brody/agnesvarda-and-jrs-faces-places-honors-ordinary-people-on-a-heroic-scale.

GDPR. "Right to erasure ('right to be forgotten')." Article 17. gdpr-info.eu/art-17-gdpr/.

Mayer, So. The Cinema of Sally Potter: A Politics of Love. New York and London: Wallflower Press, 2009.

\section{Filmography}

Varda, Agnès. Cléo de 5 à 7 . Athos Films, 1962.

- Les Glaneurs et la glaneuse. Ciné Tamaris, 2000.

_Les Plages d'Agnès. Ciné Tamaris, 2008.

— Varda par Agnès. Ciné Tamaris, 2019.

_ Visages Villages. Ciné Tamaris, 2017.

\section{Author Biography}

Tomas Elliott has a PhD in Comparative Literature and Literary Theory from the University of Pennsylvania, specialising in Anglo-European film adaptation and theory. His previous work has been published in Adaptation, and his translation of The Limit of the Useful by Georges Bataille is forthcoming with MIT Press. 